\title{
El eterno deleite de la imaginación. Idea de la imaginación en el Romanticismo, especialmente en William Blake
}

\author{
The Eternal Delight of the Imagination. \\ Idea of the Imagination in the Romanticism, \\ above all in William Blake
}

\author{
Roger Ferrer-Ventosa \\ Universidad de Lisboa \\ roger.ferrer.ventosa@gmail.com
}

\section{Resumen}

Desde finales del siglo XVIII los conceptos de razón e imaginación se transformaron en la cultura europea, con la segunda como facultad privilegiada de la mente humana para los románticos. En el presente texto se mostrarán ejemplos del incremento en la estima de la facultad, que gozó de su apoteosis en la original estética de William Blake. El artista servirá como autor por antonomasia de una tendencia común durante varias décadas, actitud romántica de la que él probablemente constituye el ejemplo paradigmático; también se comentarán sus influencias, pensadores neoplatónicos y místicos ocultistas como Böhme o Swedenborg.

Palabras clave: Imaginación, estética, romanticismo, William Blake, razón, imaginal.

\section{Abstract}

Starting at the end of the eighteenth century, in the European culture took place a transformation of the concepts of reason and imagination, with the latter being a privileged ability of the human mind for the romantics. In this text, it will be shown examples of the increase in the appreciation of that ability, whose apotheosis can be observed in William Blake's original aesthetics. The aforesaid artist provides an example of a tendency that was common during various decades, a romantic attitude of which he is the prime example; it will also talk about his influences, neoplatonic thinkers and mystic occultists such as Böhme and Swedenborg.

Keywords: Imagination, aesthetics, romanticism, William Blake, reason, imaginal. 
En las siguientes páginas se pretenden exponer los principales lineamientos de la teoría de la imaginación presentes en la obra de William Blake, un artista cuya noción estética tomaba esa facultad como piedra axial sobre la que cimentar sus propuestas. Es por tanto crucial discernir de qué manera Blake pensaba en ella; para aclararlo, se requiere de una nueva lectura de los textos blakeanos (y de otras fuentes primarias románticas), así como el análisis de su producción visual, analizados buscando sus teorías sobre la imaginación.

Asimismo, el campo de conocimiento sobre ese aspecto se ha incrementado mucho en los últimos años, ya que han surgido nuevos investigadores que, a partir de un estudio sistemático de las fuentes neoplatónicas y herméticas, y de un conocimiento mucho más amplio del misticismo, el espiritualismo o el ocultismo del siglo xvIII, han aportado nueva luz sobre el artista. Entre esos autores cabe citar a la precursora Kathleen Raine, a Patrick Harpur o a Gary Lachman. También formarán parte del corpus de fuentes secundarias especialistas en el misticismo o el esoterismo occidental desde el ámbito académico, como algunos precursores de hace algunas décadas, como Henry Corbin o Antoine Faivre, más alguno de sus sucesores actuales.

Por tanto, esclarecer qué consideraba Blake imaginación servirá para ahondar en la comprensión de su planteamiento y de su obra, algo crucial dado que Blake ha devenido uno de los artistas más influyentes desde el surrealismo, proyectando su sombra hasta el presente.

\section{La comunidad imaginativa romántica}

Las primeras grietas del poderoso sistema que otorgaba la primacía a la idea de razón del siglo XVIII se formaron con el Romanticismo.

Durante la era de la Ilustración, la capacidad de imaginar había perdido buena parte de su prestigio previo o, cuanto menos, había adquirido nuevos enfoques, en un proceso paralelo al cambio de punto de vista característico del periodo. Según el historiador de las ideas Cassirer, en aquella época: "La imaginación aparece, no como camino para la verdad, sino como manantial de todas las ilusiones a que está sometido el espíritu humano, en el conocimiento natural, y asimismo en el ético y en el metafísico" (312). Otros historiadores de la cultura como Horkheimer y Adorno ahondaron en esa línea de pensamiento. Según ellos, el proyecto filosófico racionalista tuvo como objetivo cercar la facultad, regularla, someterla a la superior jerarquía del raciocinio, "pretendía disolver los mitos y derrocar la imaginación mediante la ciencia” (59).

Entre diversos ejemplos paradigmáticos que se podrían aducir de dicha tendencia, se han espigado tanto a Hobbes como a los empiristas del XVIII; en ambos casos, la propuesta estética de Blake fue una respuesta a la de estos, ya que el artista los consideró como antítesis de lo que él propugnaba. 
En la concepción de Hobbes, este expuso su idea de la imaginación hacia el inicio del Leviatán; para él, la facultad deviene un mecanismo más del proceso cognitivo, como simple producto de lo sensible, lo percibido, filtrado por la memoria, que reactiva esa huella, puesto que la facultad no es más que sensación que se debilita. Esas impresiones que se pierden en el recuerdo pueden ser de dos tipos: simples y compuestas, las compuestas es cuando la mente combina dos recuerdos, como en el centauro, impresión de hombre a caballo y de caballo (9-15).

Por lo que se refiere a los empiristas, en un doble movimiento representativo de una actitud general, rebajaron su valor epistemológico, pero subrayaron su importancia en las artes; los productos de la imaginación estaban directamente relacionados con ellas; su refinada gratificación no tenía nada que ver con satisfacer los bastos apetitos sensibles. Aunque fuera un área del interés humano ni útil ni racional, sí que suscitaba un placer valioso al afectar a los sentimientos (Brewer 87).

La ontología filosófica de los autores románticos de la generación de Wordsworth o Blake rompió con el pensamiento ilustrado en cuanto querencia por el racionalismo, pese a que algunas de las ideas sobre las que establecieron su criterio estético, como lo sublime, provenían de un filósofo que nutrió tanto a románticos como ilustrados: Kant, bisagra con el siglo xviı y ejemplo de la nueva sensibilidad de finales de ese siglo.

Igual que en la filosofía, en el terreno artístico los románticos supusieron un cambio revolucionario respecto a los mesurados artistas neoclásicos. El género fantástico recibió un gran impulso propulsado por la nueva sensibilidad, en literatura con lord Byron, Mary Shelley o Poe en la generación siguiente, en las artes plásticas con Blake, Friedrich o Füssli... en todos ellos se constata la alta consideración hacia los procesos imaginativos. Como para los herméticos y neoplatónicos renacentistas, también para algunos de los románticos constituía un fundamento de la realidad. Fueron los primeros artistas y teóricos del arte románticos de finales del XviII los que aceptaron que la imaginación instruyera en lugar del entendimiento. "Se conmueve la fantasía para abrir paso a la penetración de la razón y prepararle así la entrada en el sentimiento de los oyentes" (Cassirer 367). Al subrayar lo subjetivo pusieron de relieve la facultad desde un criterio de enfatización de las impresiones personales y la creatividad fantasiosa.

El movimiento puede dividirse en dos en cuanto a su mirada sobre la vida desde criterios imaginativos: o bien como Goethe y Blake, quienes creían que la imaginación servía para transformar el mundo según la voluntad y el mundo psíquico del artista, o como segunda opción la de quienes argumentaban que lo espiritual (y la imaginación como capacidad de ello) ofrece una vía de escape de la crueldad inherente a una existencia concebida como trampa dolorosa, con la muerte como forma de huida definitiva, el arte como liberación transitoria.

Los grandes artistas y literatos del primer Romanticismo literario inglés compartieron la creencia en un orden no visible más allá de la manera de percibir el mundo de los sentidos. La imaginación era la llave que permitía abrir esta manera de ahondar en lo existente, de ahí los elogios que le dedicaran tanto Blake como Coleridge, 
Wordsworth o Keats, sobre los que se apuntará a continuación. Su originalidad fue el énfasis panteísta, no enteramente original, pero argumentado con intensidad innovadora. La imaginación era una facultad divina que se manifestaba sobre todo en el templo de la naturaleza.

Para Coleridge la facultad vivificaba la frialdad del inanimado mundo (167), un acto creador que podía beber de las aguas de lo onírico, y en el que incluso podían soñarse nuevas culturas como las expuestas en "Kubla Khan". John Keats escribiría sobre ese motivo recurrente romántico que hace indistinguibles a la conciencia de vigilia y a la de los sueños en los últimos versos de su "Oda a un ruiseñor”: “¿Duermo o estoy despierto?" (173).

Si volvemos a Coleridge, el poeta inglés valoraba la cualidad como el instrumento supremo de las actividades creativas o espirituales (167), una herramienta con la que transformar el gris y amenazante mundo de la vigilia. En su Biographia literaria el poeta separa imaginación de ilusión, imagination vs. fancy. La primera es el primer agente de la percepción humana y la versión microcósmica del espíritu de creación universal; con ella se iguala el acto de la creación cósmica en el microcosmos humano; la segunda es la vulgar fantasía. El poeta inglés ofreció una teoría de la imaginación en la que esta se dividía en dos modos, el primario y el secundario. La imaginación primaria de Coleridge incumbe a aquello relacionado con lo sagrado, lo numinoso, lo sublime. Si lo que categoriza la experiencia de la imaginación primaria es lo sagrado, la secundaria se ciñe a lo hermoso y pertenece a lo artístico. La cualidad disuelve, separa, reunifica, para poder crear. En cuanto a la ilusión, es un modo de la memoria que opera a partir de las asociaciones (167). Lo sublime excede las capacidades de la razón para comprender las grandes ideas filosóficas, como sentenció Kant, pero el poeta matizó al filósofo, al añadir que en cambio no excedía a la imaginación.

Para Coleridge - o para Blake, como se constatará más adelante- el acto imaginativo resalta como fundamento vital; permite una realización plena y definitiva de la condición espiritual y divina del ser humano, que lo iguala a los dioses. La consideraban a tal altura que ella participa de la actividad creadora cósmica. En ella radica un poder vital agente de cualquier acto percibido, repetición en la mente humana de esa creación universal. ${ }^{1}$ En ello se manifestaba en oposición a la filosofía utilitarista en boga en su época (Whale 166-168).

Los románticos tanto ingleses como alemanes compartieron interés por dichos autores, sobre todo durante su periodo de formación. Los primeros pasos de Coleridge los dio como admirador de Berkeley, por ejemplo, con su idealismo radical. Únicamente poseen existencia verdadera espíritus e ideas, y lo que percibimos del mundo es en realidad una plasmación de los pensamientos de Dios (Warnock 107). Böhme

1 Gómez de Liaño también apunta el sustrato neoplatónico de Coleridge y dicha raíz en ese planteamiento, que el pensador español detecta ya en antecesores del neoplatonismo - herederos del pitagorismo y del platonismo-, como Apolonio y Filóstrato (171). 
es otro autor a quien el poeta admiraba enormemente, lo que se deja traslucir en esa alta consideración que hemos mencionado hacia la potencia creativa humana o hacia la imaginación, entre otras ideas compartidas, místico hermético autor de referencia también para Blake, según se apuntará. ${ }^{2}$

El neoplatonismo, tanto de los clásicos de la Tardo Antigüedad como de su recuperación renacentista con Ficino o Agrippa también marcó su forma de mirar, algo lógico si se tiene presente el placer ante el pasado mítico en su doble forma pagana (Grecia, Alejandría) y cristiana (gótico) y su fusión en la Italia del quattrocento y cinquecento. De Keats, por ejemplo, escribe Alejandro Valero en su prólogo de las Odas y sonetos, que deseaba "revivir los mitos clásicos y el paisaje cultural renacentista" (10).

Fueron tantas las influencias compartidas entre románticos alemanes e ingleses que, por ejemplo, a Coleridge se le acusó de haber plagiado a otros románticos germánicos como Schelling, pero él arguyó que lo que compartía con ellos era haber leído a los mismos autores durante su formación (Harpur, El fuego secreto 296). A todos ellos les marcaron enormemente los citados pensadores neoplatónicos, herméticos y heterodoxos citados hasta ahora, como Plotino, Böhme o Bruno.

Al tomar como referente a filósofos como Plotino o Ficino, magos como Agrippa o místicos como Böhme, los románticos se postulaban en las antípodas del racionalismo o como un movimiento diferente a la Ilustración. Concibieron al logos activo como el acto espiritual supremo, pero desligándolo de la razón discursiva, que representaba poco menos que el pecado original (Starobinski 148).

Fue Coleridge quien despertó en William Wordsworth el interés por la imaginación y la reflexión a propósito de sus singularidades. De hecho, Barth los relaciona: si Coleridge fue el gran teórico de la facultad, Wordsworth fue su practicante supremo (1-2). Wordsworth planteó tres maneras en que se aplicaba la facultad: como paso previo de la percepción, como imagen de cosas vistas en anteriores ocasiones o como parte de la expresión del artista, una descripción en la que faltaba un cuarto punto: mediador con la dimensión sutil. El poeta discurrió una descripción de la que se deducía la importancia de la naturaleza, una preeminencia en la que se hacía notar el amor a los bosques de los románticos. ${ }^{3}$

William Wordsworth estaba de acuerdo con la analogía con lo divino: defendía como su amigo de juventud Coleridge que la capacidad imaginativa del ser humano

2 Para Böhme, la imaginación constituye un órgano fundamental, puesto que permite experimentar lo otro a él, todos los niveles de existencia. La facultad humana resulta una copia imperfecta de la divina, la primera crea cosas impermanentes, mientras que la superior puede producirlas imperecederas. La imaginación creativa o mágica böhmeana permite incluso sondear los orígenes abisales del mundo, como hizo el propio zapatero místico. Esa facultad divina tiene una doble naturaleza de capacidad y al tiempo de reino, una dimensión imaginal que regenera el mundo continuamente y, por consiguiente, en una faceta no solo personal de la imaginación sino comunitaria (Faivre 79; Levi Ian Gentzke 115).

3 En su estudio The Suffering Traveller and the Romantic Imagination, Carl Thompson vincula el placer por el viaje como inspiración artística que demostrará Wordsworth con sus lecturas juveniles de libros de viajes, que azuzaron su imaginación, marcaron su placer por las caminatas y le sirvieron de acicate poético (197-206). 
se parecía al poder creativo de Dios; él la entendía como la cualidad más elevada del raciocinio; ella facultaba para ejercer de agente del impulso creativo en la vida. Por ejemplo, en el "Preludio" a las baladas líricas, el poeta informa de que expondrá cosas que le sucede a la gente común, pero haciéndolas insólitas y coloreándolas con la imaginación (285).

En su obra se deja traslucir que intuye una realidad trascendental pero, al contrario que en el gnosticismo o en otras tendencias cristianas, el reino de Dios no pertenece únicamente a lo ultramundano, sino que puede experimentarse en el mundo físico, algo que ya se encuentra en la teoría de la belleza de Plotino. ${ }^{4}$ Es más, el poder de abrir la imaginación puede obtenerse gracias a la contemplación o a la vida en la naturaleza. La experiencia contemplativa de reunión con lo esencial o de imaginación creativa aplicada a su poesía intenta rebosar de una verdad primordial de sentido panteísta. El progresivo incremento de población en las ciudades originado por la revolución industrial fue criticado y equilibrado con el elogio de los espacios con vegetación, ya que en ellos al poeta le resultaba más fácil conseguir el estado de ánimo maravillado y al tiempo lúdico.

Los artistas románticos se acercaban a la naturaleza para, aprovechando la descripción artística, transmitir la belleza y el misterio en ella, con el estudio idealizado de paisajes naturales como uno de los motivos más habituales de creación artística a finales del XVIII y principios del XIX. La inspiración alcanzaba a William Worsdsworth a partir de dos focos emotivos: el arrobo - y también cierto escalofrío de terror sublime- por la naturaleza y el peso de la nostalgia por la mirada infantil, como poetiza en su "Oda a la inmortalidad":

Though nothing can bring back the hour

Of splendour in the grass, of glory in the flower;

We will grieve not, rather find

Strength in what remains behind. ${ }^{5}$

En sus años de plenitud poética, William Wordsworth creía acceder a otra realidad haciendo uso de su poder para la ensoñación o su talento literario; a ese otro reino se accede no a través de los sentidos sino gracias a la potencia visionaria. Ese otro mundo le permitía superar las ligazones de lo terrestre o del cuerpo físico, "cuando el poeta tenía esta experiencia sentía que había entrado en la eternidad, por encima

4 En el sistema de Plotino el salto de lo sensible hacia lo inteligible permite una experiencia de lo Bello. Su sensibilidad se opone a la postura gnóstica: cree en el "panorama de bellezas que hay en el mundo sensible, al ver un conjunto tan bien proporcionado y este grandioso y perfecto ordenamiento" (Enéada II 9, 15, en Plotino y Porfirio 530). Si ya el universo es bello, podemos imaginar cuán hermoso será su creador, argumenta Plotino, con la Inteligencia primordial como la más bella de las cosas, de la que el bello mundo es sombra (Enéada III 8, 11, en Plotino 258-260). El universo físico retiene una fragancia del mundo inteligible a través de lo bello. Esa idea de la belleza del mundo como emanación de lo inteligible ha mantenido a los neoplatónicos "alejados de la idea de la caída de Sophia, en la forma que le dieron otros sistemas de gnosis" (Corbin, La imaginación creadora 194).

5 http://www.bartleby.com/145/ww331.html (Última consulta 5 de febrero de 2020). 
del tiempo" (Bowra 105). El poeta ya disfrutaba de esos poderes en la infancia, es más, precisamente era entonces cuando tal capacidad se poseía en mayor plenitud. Incluso Wordsworth los proyectaba hasta antes de la gestación, en una teoría de la reminiscencia prenatal de resonancias platónicas.

Si la relación de los autores ingleses con el hermetismo o con una teoría y práctica de la imaginación fue más bien conceptual, para concretarse en teoría literaria, en el caso de Goethe el vínculo fue todavía más estrecho, ya que el gran literato incluso hizo sus pinitos con la alquimia (Lachman, The Quest for Hermes posición 3895 y ss.). Además de a otros herméticos —en sentido amplio-, Goethe estudió a Paracelso.

Ello comportaba que, como en tantos otros estetas con influjo hermético de aquellos años, Goethe aunara en sus intereses aspectos tomados por opuestos dentro del horizonte cultural ilustrado racionalista; unió ciencia, arte, pensamiento mágico y espiritualidad en un conjunto no dual, que evitaba considerarlos antitéticos. Esa mirada sobre las cosas tuvo un correlato incluso en su forma de comprender la naturaleza como fenómeno, en la que integró en un todo coherente observación empírica e intuición espiritual.

Por lo que se refiere al arte, en su escrito sobre Winckelmann Goethe expone los valores de la belleza y la armonía de regusto hermético y neoplatónico con su elogio de lo bello; el poeta estima el arte, primordial para él, merecedor de un lugar esplendoroso. La obra suscita un efecto duradero, el más supremo, ya que al actuar espiritualmente acoge lo más grande y venerable, "absorbe en sí y eleva todo lo magnífico y digno de admiración y aprecio" (Goethe 189). Debido a ello puede elevar el alma del hombre, darle fuerzas anímicas de tal manera que llega a divinizarlo, una idea ya acariciada por los poetas ingleses previamente comentados.

El poeta alemán establecía que el uso de la imaginación pertenecía a un reino intermedio entre el ideal arquetípico y la manifestación. En la lectura realizada por Gary Lachman, con una observación atenta, clarividente, se podía aventurar cómo se desarrollaría un proceso antes de que se hubiese desplegado por completo, ya fuera el crecimiento de la vegetación, ya fuera la construcción de una catedral — de la idea al plano y de este a la edificación material- Se trataba de averiguar cuál era el arquetipo genésico de cada uno de ellos (The Quest for Hermes posición 3917).

Por su parte, también Schelling reflexionó sobre la facultad; el talento para crear del hombre se debe a los dos niveles de lo imaginativo, uno inconsciente, que es como se engendra en la naturaleza, y otro consciente, que es aquel que canaliza la fuerza de innovación en forma de arte. Como en Kant, Schelling estimaba la cualidad como una manera de captar y de comunicar las ideas, de percibir la esencia ideal de las cosas; el artista ha de inventar nuevas imágenes y símbolos con las que expresar la naturaleza última de lo existente (Warnock 66 y ss.)

En resumen, en dichos autores, así como en otros de aquellos años, se detecta durante el Romanticismo un enorme rebrote de la confianza en lo imaginativo y los reinos y poderes que despliega: "Se ha dicho que el movimiento entero ha sido un 
renacimiento de lo maravilloso y este título es justo" (Bowra 305). Para ello, se hacía necesario un ánimo de apertura combinado con cierta candidez, el espíritu característico de la infancia añorada, justo cuando más amplia es la capacidad de imaginar. La libertad del niño que se maravilla en los bosques, su manera despreocupada de encarar la existencia, fue un motivo recurrente de tantos poetas románticos.

\section{William Blake como emblema de artistas "imaginativista"}

De entre todas las ideas románticas sobre la imaginación, sobresale con destellos multicolores las manifestadas por William Blake, tanto que resulta imprescindible dedicarle un lugar de honor como artista imaginativo. Cabe recordar que la exposición de sus ideas sobre la imaginación se realizará partiendo de sus obras como fuente primaria, pero también de algunos analistas afines a su universo poético, como Lachman, Harpur o Raine, tomados como fuentes secundarias.

El poeta, pintor y grabador descuella como ejemplo paradigmático del uso de la imaginación a finales del XVIII y principios del xIX, plasmador en buena medida de una noción demiúrgica de ella aplicada a la estética. Probablemente sea él el máximo exponente de dicha idea en la historia del arte, al menos tal y como se ha desarrollado en Europa. Blake supo reconfigurar el rango de lo existente y lo real según su propio criterio, no solo por el peso de la facultad, sino también por su carácter rebelde, doble motivo que le impulsó a reformular la realidad de acuerdo con su fuerza creativa.

Blake condenó al pensamiento racional, entendido, eso sí, exclusivamente como abstracción, ya que la mentalidad que creaba era digna del Ulro, dentro de su mitología particular el estado del ser más bajo, aquel que cree únicamente la regla y la línea recta (Bowra 307). El pensamiento debía basarse en la capacidad imaginativa, por tanto, huir de las abstracciones que fosilizan lo existente. En Milton: poema en dos libros declara que ha llegado para relegar la demostración racional, sustituida por poesía inspirada engalanada de imaginación (Blake, Libros Proféticos II 153).

La creatividad aportada por la imaginación transforma lo real, una de las atribuciones asignadas al verdadero artista. "Lo que hoy está probado, antaño fue sólo imaginado" (Blake, Libros Proféticos I 97). Como ya se vio al referirse a las influencias de los románticos, algunos de sus referentes a su comprensión encomiástica de la facultad pueden hallarse en los herméticos renacentistas. En palabras de Lachman: "Blake's Humanism is much more the 'superhumanism' I spoke of earlier in relation to Pico, with its celebration of human imagination and creativity as supreme powers" (Lachman, The Quest for Hermes posición 3214).

Es tan notorio el elogio y el valor otorgado a la facultad que, para algunos exegetas, entre ellos Harpur, en ella descansa la principal característica del autor inglés; en la transvaloración efectuada por Blake es la imaginación la que posee la primacía en el alma humana, no la razón (Harpur, "Introducción a los Libros proféticos" 12). 
En una conversación entre los Siete Ángeles de la Presencia y Lucifer en Milton: poema en dos libros, en un diálogo conformado por estos ocho personajes, sin que se distingan voces entre ellos, se sentencia: "La Imaginación no es un Estado, es la propia Existencia Humana" (Blake, Libros Proféticos II 123); no pertenece por tanto a lo pasajero y cambiante sino a lo eterno e inalterable.

Si para los físicos mecanicistas la mente funcionaba como espejo pasivo de una naturaleza mecanizada, para Blake era el campo de juego original del que partía todo, humanos, animales, plantas y objetos (Raine 28). Lejos del paradigma del xvin que empezaba a pensar en la mente como impresiones causadas por las percepciones en un original impoluto, la tabula rasa, Blake defendió un fondo imaginal —en términos de Henry Corbin $-{ }^{6}$ de todo en el que, neoplatónicamente, la materia y lo captado por los sentidos sería una sombra de los reinos de la imaginación.

Lo material acontece en la imaginación universal, base necesaria de la que emerge lo múltiple. La imaginación devendría así el Uno, en términos plotinianos o al menos es una de sus virtudes, aquello de lo que emana todo lo que existe. ${ }^{7}$ En la nomenclatura que utiliza en sus poemas para crear su universo particular, la imaginación puede aparecer bajo el nombre de Jesús o del Hombre Verdadero. ${ }^{8}$

Para el poeta y artista plástico, en ella hay unas imágenes eternas e independientes del ser humano, en una teoría del arquetipo neoplatónica pero que lo concibe más en forma de imagen. Y el peso de esta escuela no terminaba ahí; era neoplatónico también en su noción del alma, concebida según el criterio de una existencia previa a la encarnación física; para él, las almas viven antes de entrar en la corporalidad material; en esa dimensión etérea, escogen su destino por afinidad; igualmente, retornan a una realidad más sutil al abandonar el cuerpo cuando este fallece, previo paso a una nueva encarnación, como queda más o menos ilustrado en La pintura de Arlington Court descrita por Kathleen Raine como el descenso de las almas en la vida sensible y su posterior retorno al abandonar el cuerpo (155-156).

Otra de sus grandes influencias, asimismo con mucho de neoplatónico, fue el místico ocultista Swedenborg, autor clave. Blake bebió de Swedenborg y del herme-

6 Corbin adaptó el término del árabe alam al-mital. Los mundus imaginalis son "el mundo autónomo de las figurasarquetipos" (Corbin, El hombre de luz 61), un producto de la imaginación, o al menos esta sirve de llave para abrirlos, que se despliegan en universos atópicos, sin unas coordenadas físicas según los parámetros de la física de la ciencia mecanicista estándar (Corbin, La imaginación creadora 254 y ss.) En el horizonte cultural platónico y neoplatónico, el anima mundi sería lo más parecido. De hecho, fue pensado por pensadores islámicos muy influidos por esas escuelas.

Locke y su tabula rasa constituyó uno de los pensadores más atacados por Blake. A modo de ejemplo entre muchos otros, de él escribió en Milton: "para relegar a Bacon, Locke y Newton de la cobertura de Albion; / para despojarlo de sus sucias vestiduras y engalanarlo de Imaginación” (Blake, Libros Proféticos II 153).

7 En vez de con el neoplatonismo, Antonielli traza relaciones con la Kabbalah (341). También esboza dichos vínculos Spector (175).

8 En alguna de las ediciones de Milton, en páginas extras que no aparecen en el resto de ediciones, el poeta escribió: "And of the sports of wisdom in the Human Imagination, / Which is the Divine Body of the Lord Jesus blessed for ever”. Página 46 en la edición online de las obras de William Blake: http://www.archive.org/stream/propheticbooksof00blak/propheticbooksof00blak_djvu.txt (Última consulta 5 de febrero de 2020). 


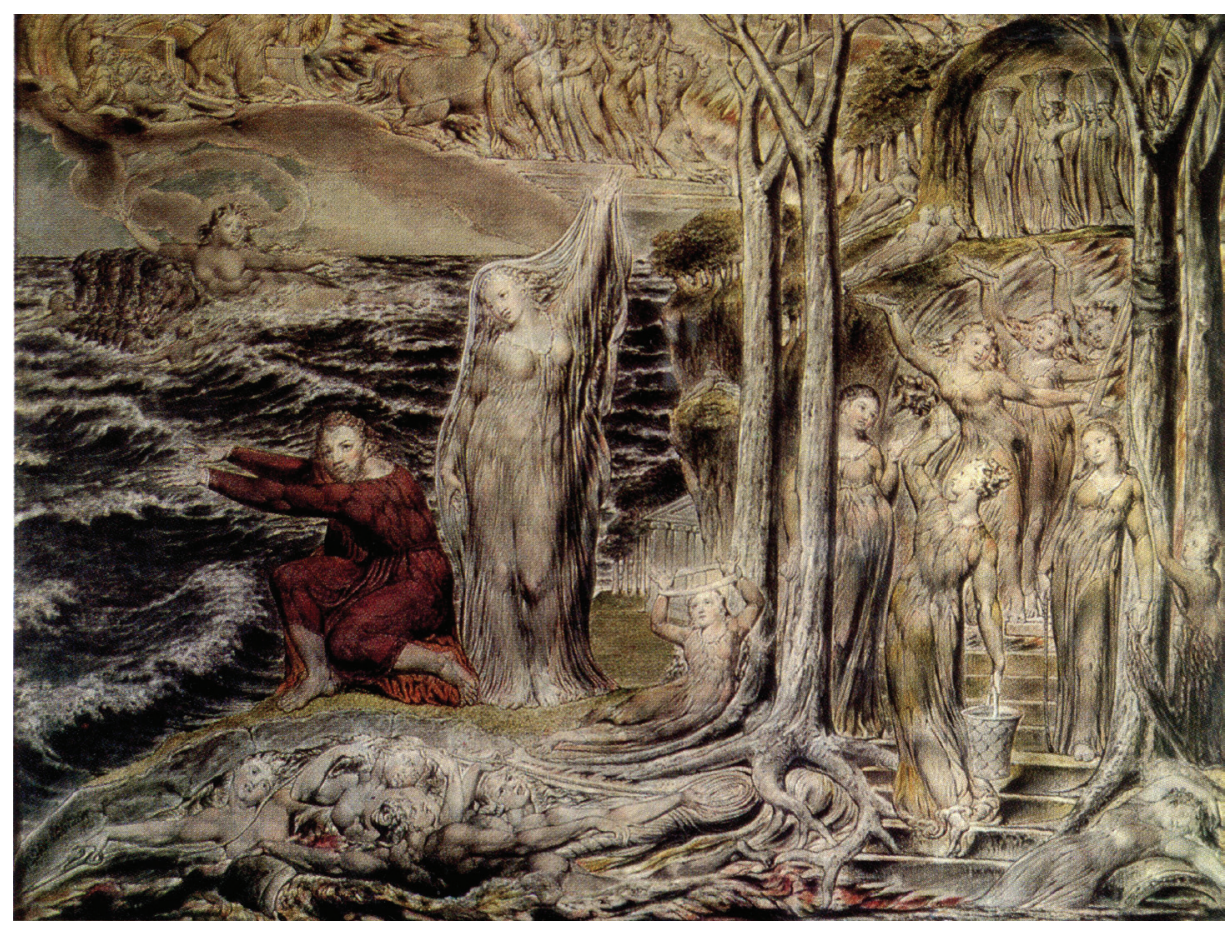

\section{FIGURA 1}

William Blake, La pintura de Arlington Court, 1821. Dominio público.

tismo, aunque en un sentido amplio y genérico; y es que "Blake saw himself as a poet in the hermetic tradition, drawing on the rich underground stream of ancient magical and occult knowledge, and hammering out in his didactic and aphoristic verse a new synthesis of what she calls the 'perennial philosophy"' (Lachman, A Dark Muse 58). Tanto sus referencias como su universo personal inciden en la cosmovisión mágicohermética. En Milton: poema en dos libros Rintrah y Palambron dicen de Swedenborg: “El más fuerte, el Sansón rapado por las Iglesias!” (Blake, Libros Proféticos II 83).9

El tipo de humano propuesto por el artista con el personaje de Los alcanza todo el cosmos con su facultad imaginativa, con los sentidos ilimitados, fruto de su identidad con el mundo, un poco una personificación de ella, un ser demiúrgico a lomos de la imaginación creadora, símbolo del genio poético, según expresa acertadamente An-

9 Pese a ello, en El matrimonio del cielo y del infierno dejó escrito con severidad que Swedenborg no había escrito ni una verdad nueva, y que recapitulaba opiniones superficiales y analizaba las más sublimes, "pero nada más" (Blake Libros Proféticos I 115). El artista poseyó al menos tres de los libros del místico, con sus correspondientes anotaciones de puño y letra blakeana (Spector 173-174). También se cita a Swedenborg como influencia en Lahelma (37). 
tonielli (340, n. 32). Un genio poético del artista genuino que parte de lo imaginativo y no de un mero dominio de una técnica (J. Wordsworth 527).

Pero el progresivo crecimiento de la razón cierra los sentidos, que se circunscriben a validar únicamente lo registrado en la dimensión física efectiva, tendencia cognitiva tomada finalmente como la única posible. Pero la facultad imaginativa permite al tocado por Los liberarse de las cadenas de la red mental. En una de las láminas de Milton: a Poem el alter ego de Blake en la obra recibe la fuerza imaginativa de Los. Se le representa iconográficamente dentro de un círculo, en una representación que toma del tipo renacentista del hombre perfecto.

Para Blake, no es que el ser humano sea una minúscula fracción del universo, como afirma el materialismo, sino que su imaginación divina -o la imaginación divina que hay en el ser humano- contiene todo el universo. El cuerpo material del ser humano es un reflejo de su espíritu inconmensurable, no limitado ni por tiempo, ni por espacio o forma. De los mundos inabarcables de la imaginación surge el reino de lo cuantificable, lo físico, creado en la particular mitología de Blake por el demiurgo Urizen, la Mente Eterna, Pantocrátor de Newton que teje la urdimbre de

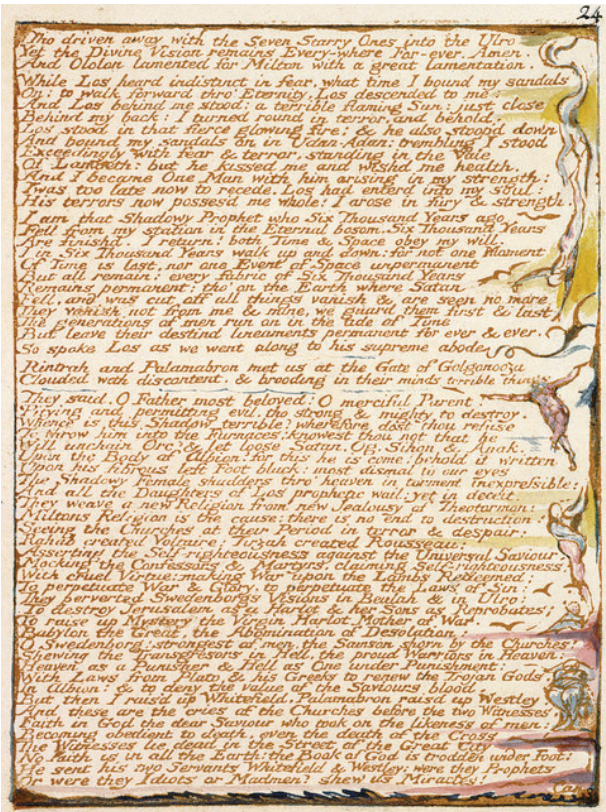

FIGURA 2

William Blake, Milton: A Poem, 1811, página 20, líneas 51-52. Dominio público.

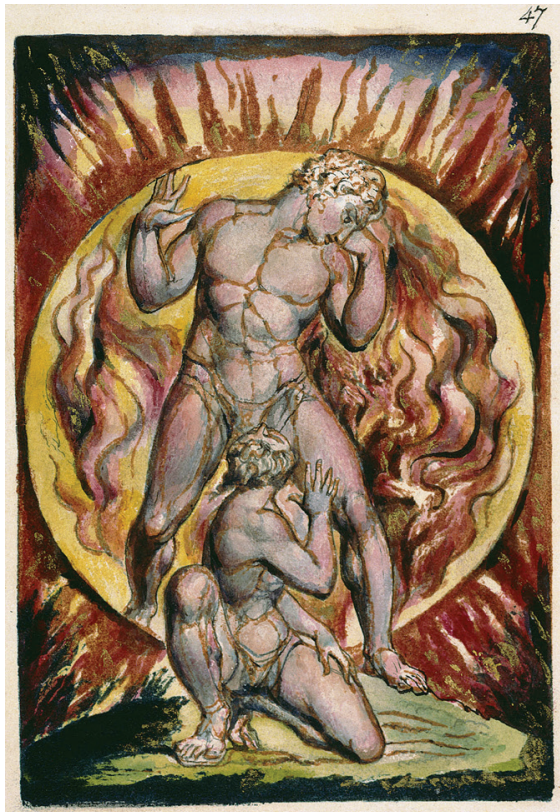

\section{FIGURA 3}

William Blake, Milton: A Poem, 1811. Dominio público. 
Locke, en vivaz expresión de su creador (Blake, Libros Proféticos II 25). Pero igual que hay la dimensión dualista de lo limitado regida por Urizen — sería el equivalente de Yahveh-, existen los cielos de Beulah, paraísos que reflejan los deseos del soñador. Se trata de estadios donde la imaginación se presenta en sus formas más puras.

El mundo físico así emanado tenía un carácter ilusorio, entendido en el sentido de no absoluto y generado. "La Naturaleza es, así pues, una Visión de la Ciencia de los Elohim” (Blake, Libros Proféticos II 113), sentencia con la que termina el primer libro de Milton. El personaje del universo mitológico del artista que sirve como alegoría de lo físico, Vala, si se desliga de la verdad esencial, del espíritu fundador, se convierte en una sembradora de cadáveres, como la Kali hindú, la madre terrible con un collar hecho con las calaveras de aquellos a los que aniquila. La faceta material desligada del espíritu genera una humanidad desgarrada, en guerra permanente. Separada de su fundamento, Vala degenera en una maldición destructora.

En su largo poema Jerusalén: la Emanación del Gigante Albión explica que los cuatro Zoas cósmicos se convierten en Espectros al adentrarse en lo que llama el Poder Razonador y al desdeñar la Imaginación, y en una estrofa que denota su pensamiento en esta obra madura, recita con voz profética:

El Espectro es el Poder Razonador en el Hombre, y cuando se separa

De la Imaginación y se encierra como en acero, en una Proporción

De las Cosas de la Memoria, ¡entonces formula Leyes y Moralidades

Para destruir la Imaginación!, el Cuerpo Divino, por medio de Martirios y Guerras (Blake, Libros Proféticos II 427).

Al escindir al ser humano de la perspectiva imaginativa, como sucede en los sistemas filosóficos racionalistas, se lo condena a una pérdida de la experiencia, con una reducción al mínimo que suponen los datos cuantitativos. Experimentar se reducirá para los filósofos ilustrados o positivistas en un proceso pasivo de mera recepción de los estímulos recibidos en un universo en que cada parte es el engranaje de un mecanismo general. La experiencia cuando se incluye a la imaginación es recogida en el ojo interno, en una visión continua que impregna tanto la vivencia como lo percibido, dando como resultado una experiencia inconmensurable, que no podrá registrarse por ninguna de las medidas y aparatos de lo cuantitativo.

El cuerpo de la imaginación de Blake no dispone de dimensiones físicas, volumen, tamaño o cuerpo material. Además, el cuerpo de imaginación no pertenece únicamente a los seres humanos, sino que, perspectiva animista, es compartido por animales, vegetales, minerales y cosas. De hecho, compartir es el verbo más adecuado, ya que en su manifestación la dimensión imaginal aparece múltiple, pero en su raíz se establece como una unidad. De nuevo aquí se hallan trazas de platonismo y neoplatonismo, con la idea del anima mundi.

Como es eterno, al morir, cuando abandona el cuerpo físico - la Cáscara en terminología blakeana - la persona retorna a la conciencia de ser. El artista adapta 


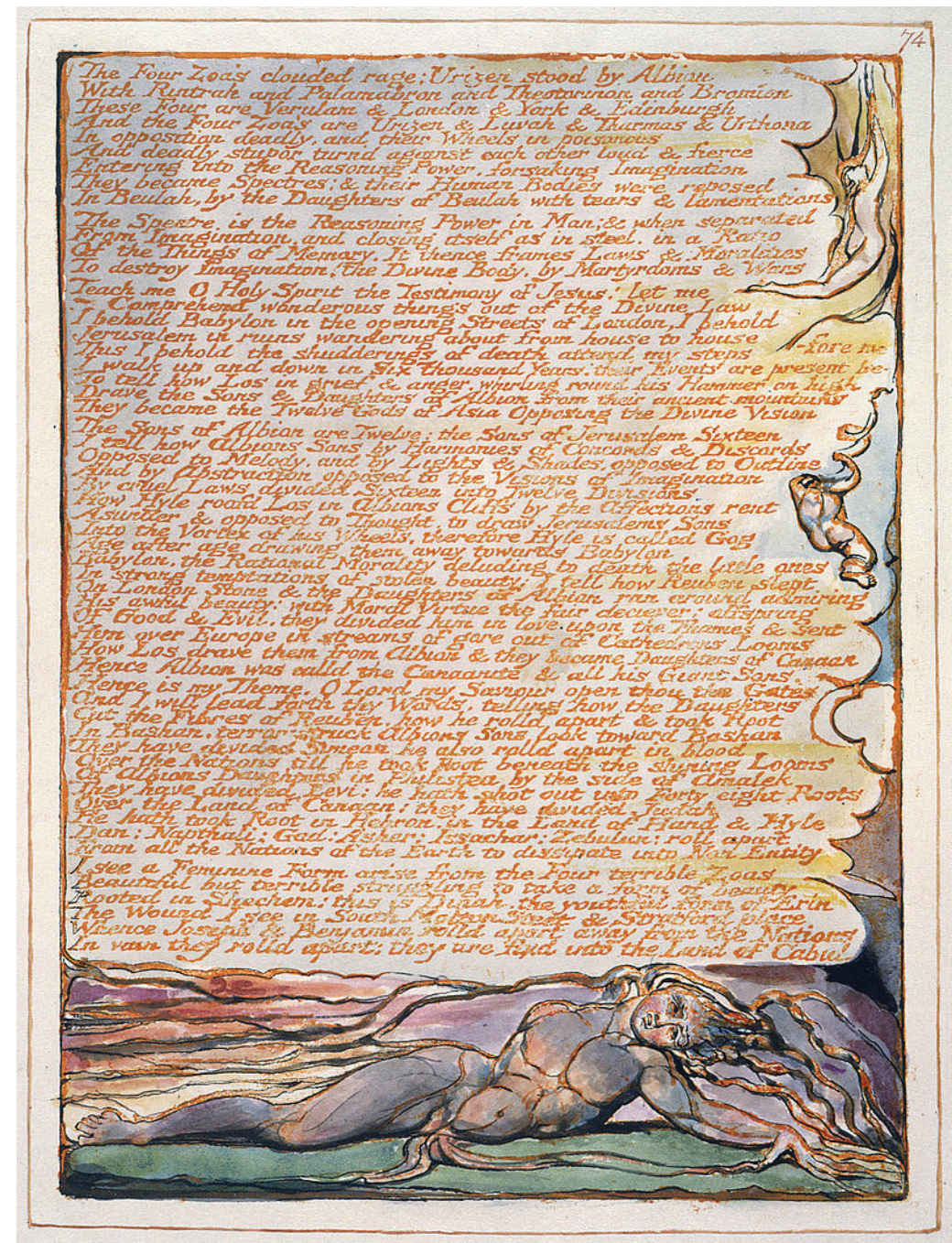

FIGURA 4

William Blake, Jerusalén: la Emanación del Gigante Albión, folio 74, 1804. Dominio público. 


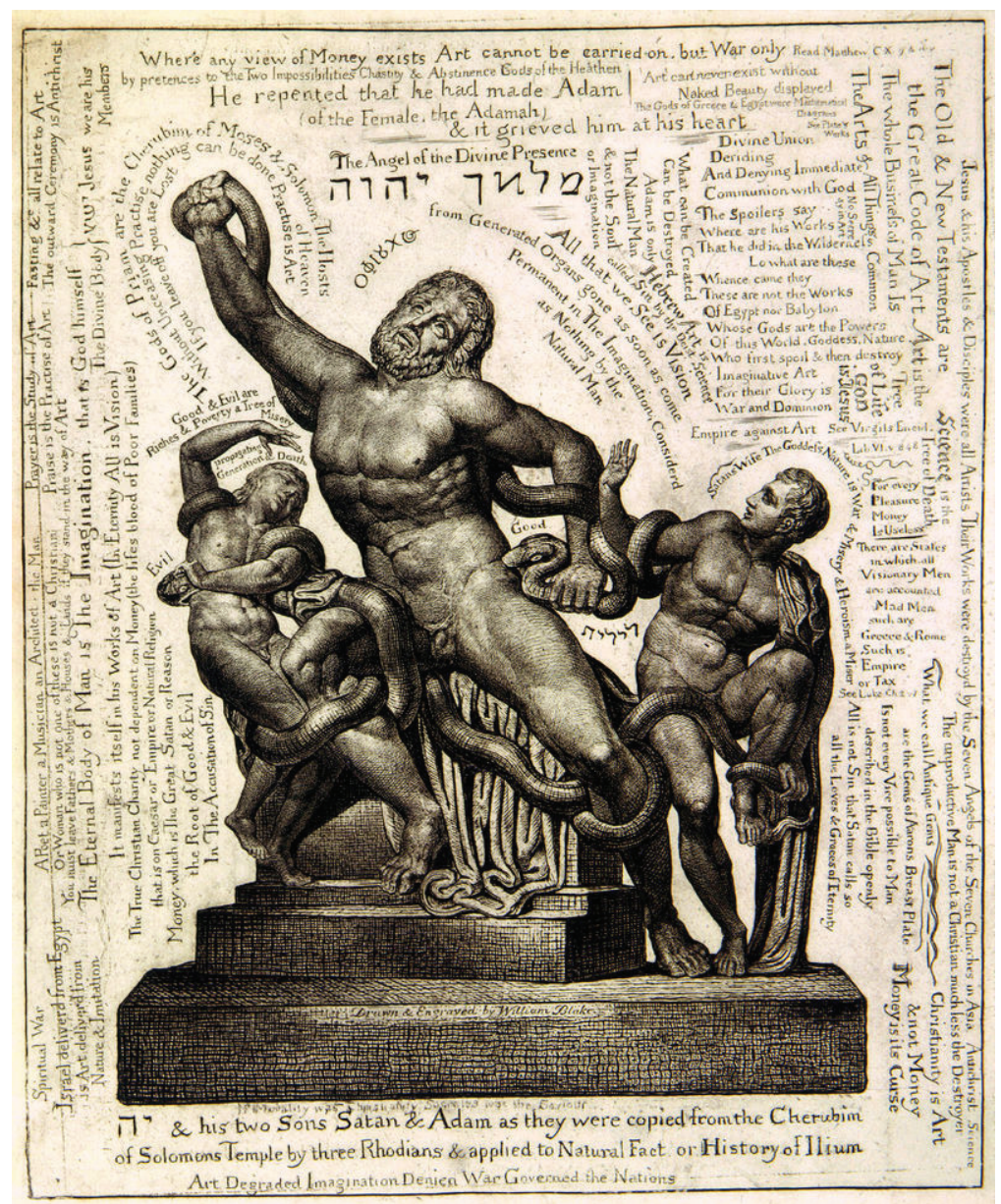

FIGURA 5

William Blake, The Laocoön, 1820. Dominio público. 
una perspectiva espiritual en la que se otorga una gran preponderancia a lo imaginativo; otra peculiaridad de su sistema es que abandona el dualismo mayoritario del pensamiento occidental: el cuerpo físico no es el antagonista del imaginativo, sino que ambos conforman un sistema unitario formado por diversas capas, con el cuerpo como capas más externas al núcleo del espíritu. Blake sobresale como uno de los pocos pensadores no duales en la historia de las ideas en Europa, en la que, tras el platonismo, el cristianismo o el cartesianismo, prima la forma mentis dual.

El artista consideraba que el resto de talentos humanos, sus emociones, sus sentidos, incluso su razón, brotaban del terreno fértil de la imaginación. "El Cuerpo Eterno del Hombre es la Imaginación, es decir, el propio Dios... Se manifiesta en sus Obras de Arte (en la Eternidad Todo es Visión)" (Raine 17), axioma que aparece inscrito en su versión del Laocoonte, esa especie de monumento grafiteado avant la lettre. El conjunto de cosas, el mundo, es el resultado de la imaginación creadora de Dios. La lucha de las figuras en el Laocoonte ejemplifica la opresión en el reino de Vala, emblema de la vida en el universo mecanizado.

Pero que Blake abogara por la creatividad máxima no implica que renunciara a partir de formas clásicas, que se apropiara de sus predecesores y los variara. Pese a la estima de Blake hacia la imaginación, conviene tener claro que no se refería con ello a la fantasía, en este caso al libre vuelo de la mente sin anclaje a sus experiencias o conocimientos, sobre todo aquellos que se refieren a lo sacro.

Aunque el tópico sobre el Romanticismo indique que sus artistas no querían copiar a los maestros, querían ser genios con estilo propio (Guillén 42-43), Blake se desmarca de esa tendencia en cuanto a la corporalidad y la gestualidad de sus figuras. Pese a valorar la creatividad, el estilo de Blake muestra influencias evidentes del Renacimiento, sobre todo en las formas de su admirado Miguel Ángel, otro artista en quien el neoplatonismo imprimió su sello.

Pero no le influyó únicamente Miguel Ángel; también admiró a Donatello o el clasicismo griego pero sin quedar sujeto a su representación anatómica naturalista o que tiende a un naturalismo idealizado; sus postulados estéticos obviamente no eran los del neoclasicismo, en el que se intentaba imitar al máximo los originales que veneraban. El estilo de Blake deja traslucir su querencia hacia las figuras de corte clásico, aunque, eso sí, finalmente sus trazos no muestran rigor al representar la musculatura o la estructura ósea. Es decir, que conocía la tradición plástica europea pero que la adaptó según su criterio personal, según unos fines estéticos particulares. Podía ser un artista visionario, pero ello no equivale a afirmar que se basara únicamente en su intuición o sus caprichos, como le acusaron tantos estudiosos durante décadas.

Blake pasó muchas horas contemplando obras y tomando bocetos, de ahí el claro regusto a la Antigüedad reformulada de sus figuras, es más, su uso de motivos de la tradición estética europea, como el Hermes crióforo o también el Moscóforo, quienes portan cargados sobre la cabeza a un animal, generalmente un ternero o un cordero, un motivo griego que perduró en el arte europeo por su transmutación en 


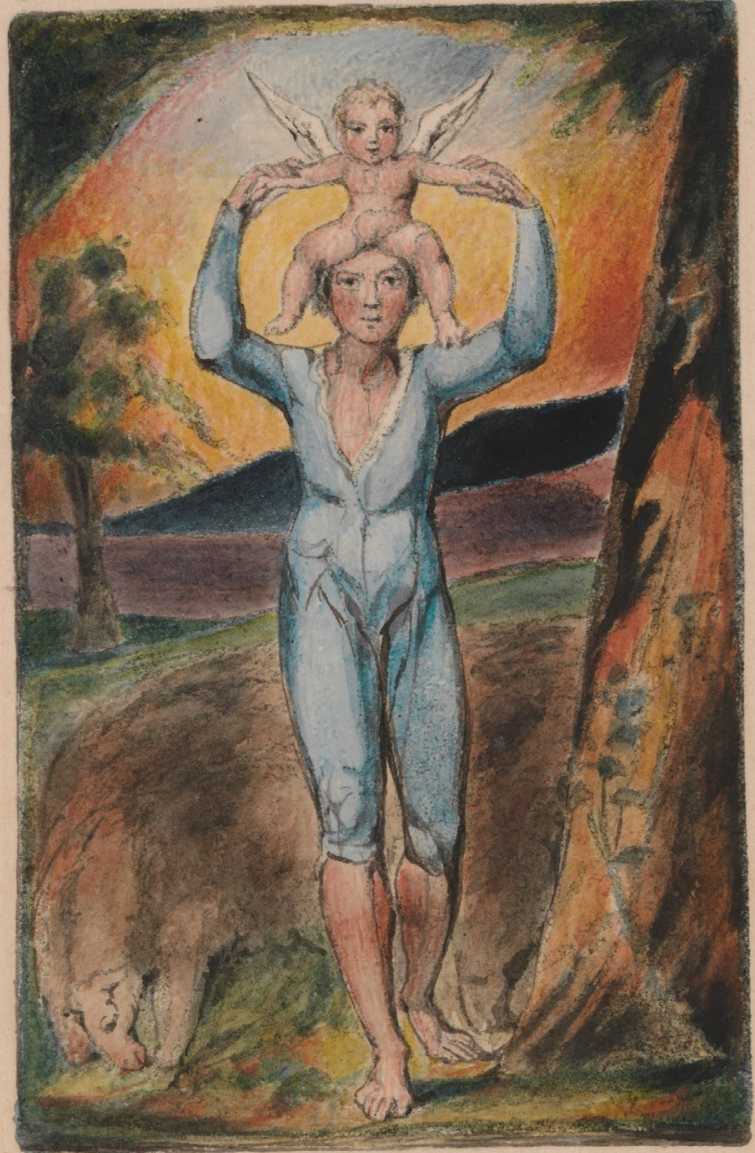

FIGURA 6

William Blake, Songs of Innocence and of Experience. Dominio público. 
motivo cristiano, con el Cristo que lleva un cordero a hombros, o el de san Cristóbal por ejemplo en el Tríptico Moreel de Hans Memling (1484). Blake utilizó dicho tipo tradicional para uno de sus grabados en Songs of Innocence and of Experience.

Otras fuentes notorias en las que el estilo de Blake se forjó son los manuscritos iluminados medievales y los libros de grabados de alquimia, sobre todo su periodo de máximo esplendor, entre los siglos xVI y finales del xvir. De estos últimos no tomó únicamente la faceta estética, sino que compartió ideas, sobre todo en lo que se refiere a su teoría de la imaginación. La razón se une a los sentidos y, por tanto, a lo mortal, mientras que la imaginación se separa de lo mortal y une a lo inmortal de la belleza.

También compartió con ellos la forma mentis no dual e incluso algunos motivos iconográficos, como la manera de representar la naturaleza perfecta, un ser en el que se reúnen el sol y la luna, es decir, la pareja de opuestos. En alquimia es un motivo típico, un ser de dos cabezas y que posee la doble naturaleza sol-luna y

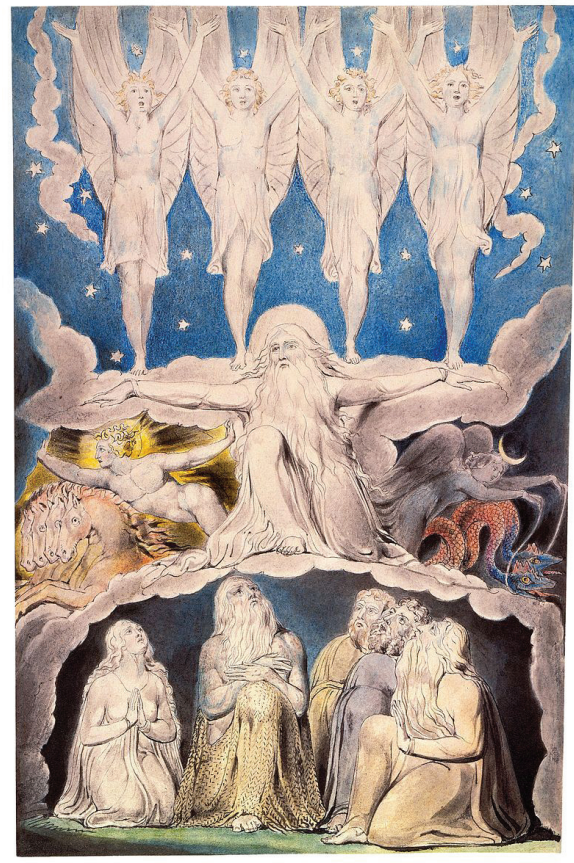

FIGURA 7

William Blake, El libro de Job, 1805. Dominio público.

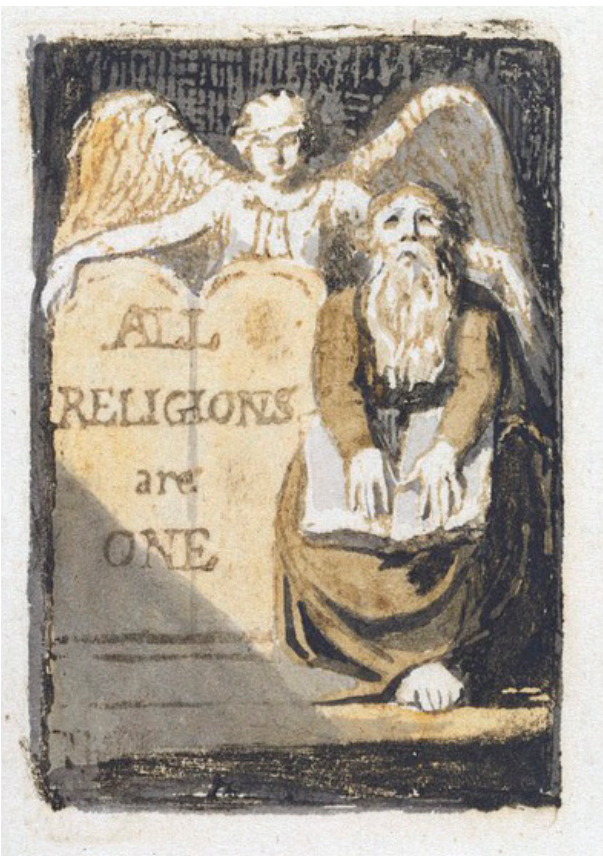

FIGURA 8

William Blake, All Religions Are One (1788-1795). Dominio público. 
macho-hembra; ${ }^{10}$ Blake adaptó la imagen al representar a Dios en la franja central de uno de los grabados de El Libro de Job, ser por definición de naturaleza perfecta y que, por tanto, reúne la doble condición sol-luna.

Con unas ideas en las que la imaginación gozaba de tal estatus, el arte tenía que ocupar un lugar privilegiado como forma de conocimiento. El pintor consideraba que la manera de manifestarse la imaginación era mediante las obras de arte, aunque entendidas de una manera muy amplia, en la que por ejemplo, podían incluirse cualidades humanas como la piedad (Bowra 47). En ocasiones simboliza a la facultad con llamas: "In Blake's work, flames often symbolise the power of imagination to consume the corrupt, finite World of the closed senses, and to open the individual to eternal life" (Lincoln 141).

En su producción, bautizó al reino interno de la imaginación como Golgonooza, de Golgos, cráneo; la ciudad imaginada — también con resonancias a Londres - construida por el esfuerzo visionario. Los reinos internos creados por la cualidad pueden materializarse y desvanecerse en un instante, fugaces como pompas de jabón, por expresarlo a lo Machado. El arte mimético que solo se fija en lo físico, es llamado despectivamente por Blake "alegoría”. Un lugar común del estudio sobre Blake radica en su distinción entre la fábula y la alegoría, productos de lo memorístico proyectados por sus procesos, que resultan enteramente diferentes e inferiores a la visión, el símbolo o la imaginación de la realidad trascendente, aquello existente por toda la eternidad, representantes de lo arquetípico, lo imaginal (por ejemplo en Yeats 150-153). ${ }^{11}$ Una idea similar de la creación, aunque en ese caso general, aparece en el Timeo platónico. Según explica Timeo sobre la creación universal del demiurgo, el artífice fija su mirada en el modelo inmutable y no en lo generado; así la creación será bella (Timeo 28c-29a, en Platón 171).

Sobre ese basarse en lo imaginal de la teoría estética de la imaginación en Blake, de claro regusto platónico, apunta Chevrier:

Toute figuration du corps est de l'ordre du tracer, puisqu'elle procède de l'imagination, puisquelle est la transcription d'une vision (et non l'interprétation d’une donnée naturelle). Blake ne rêve pas de permanence, ni de statu quo: les formes éternelles n’ont pas la stabilité d'un état fixe (115).

Antes de concluir el recorrido por lo imaginativo romántico en su máximo exponente y propugnador, conviene puntualizar que, pese al gusto por el discurso espiritualista de Blake, dado su espíritu rebelde él siempre permaneció alejado de la religión como institución de poder. Blake creía que en sus orígenes todas las religiones estaban unidas

10 Sobre el andrógino como ser de naturaleza perfecta que integra los dos géneros o el sol y la luna: Ferrer-Ventosa 320. Para una representación del tipo iconográfico andrógino en alquimia, con el sol y la luna, sirva el siguiente enlace con un grabado: https://www.e-rara.ch/cgj/content/pageview/1811706 (Última consulta 1 de febrero de 2020).

11 Como anécdota, William Blake tuvo visiones en muchos momentos de su vida. Aunque sea de las personas que más se ha basado en ellas, a menudo fue discreto, ya que en una ocasión le había explicado a su padre que había visto ángeles en un árbol, lo que ocasionó que se ganara una paliza; explicado por Gary Lachman (Lachman, A Dark Muse 57). 
en una, como titula su All Religions are One, un poco en la línea de la prisca theologia de los neoplatónicos renacentistas o de la filosofía perenne actual (Spector). Pero la religión como autoridad y poder social ha esclavizado al ser humano, fijándolo al mundo de los cinco sentidos, la realidad física sin relieves ni profundidad. En varios de sus libros de grabados ataca a la religión institucionalizada, como en Visions of the Daughters of Albion o también en The Song of Los; arremetió contra ellas como embrutecedoras, con el objetivo de mantener a la humanidad sumida en la ignorancia para beneficiarse de ese factor.

Para finalizar, cabe indicar la condición inicialmente de unicum de Blake en su momento, pero creador de escuela en las generaciones siguientes. Fue una rareza en su época dado su gusto por lo simbólico polisémico y la extrañeza de su universo, realizado en plena era ilustrada, con la estima característica de la Ilustración hacia lo conceptual, la física mecanicista, lo cuantitativo o lo racional. Durante la época de vida del artista y aún a posteriori, en buena medida los libros proféticos de Blake restaron "por mucho tiempo incomprensibles, dada su mitología desconocida cuya acción no tiene lugar en la historia, sino en los mundos internos" (Raine 250). En los imaginales, que diría Corbin.

Pese a ello, o quizás debido a dicho motivo precisamente, ha seguido fascinando a las sucesivas generaciones - de los posteriores románticos a los simbolistas, de los surrealistas a la contracultura-,${ }^{12}$ atraídos por sus poemas cosmogónicos y sus visiones tan originales. De hecho, en los últimos años se ha vivido un claro auge en el conocimiento del autor y del poder de atracción de su peculiar universo, incluido el mercado editorial hispano, merced a las últimas traducciones.

El sol central que es la imaginación en el universo de Blake no deja de iluminar y de vivificar a los lectores contemporáneos.

\section{Referencias}

Antonielli, Arianna. "As all Men are Alike (tho' infinitely various) So all Religions". On the Philosophical and Religious Underpinnings of William Blake's Cosmogony. LEA: Lingue e Letterature d'Oriente e d'Occidente, n. ${ }^{\circ}$ 6, 2017, pp. 329-343. Doi: http://dx.doi.org/10.13128/LEA-1824-484x-22021

Barth, J. Robert. Romanticism and Transcendence: Wordsworth, Coleridge, and the Religious Imagination. Columbia, University of Missouri Press, 2003.

Blake, William. Songs of Innocence and of Experience. Blake's Illuminated Books. Volume 2. Londres, Tate Gallery, 1991.

12 Como muestra representativa de muchos otros ejemplos que se podrían aducir, un fragmento de la película Dead Man (Jim Jarmusch, 1995): https://www.youtube.com/watch?v=6WfbRJYKIM0 (Última consulta 1 de febrero de 2020). Schmidgall apunta enfáticamente que Gingsberg, el poeta emblemático de la contracultura, idolatraba a Blake (133). 
- - Libros Proféticos I. Vilaür, Atalanta, 2013.

-_. Libros Proféticos II. Vilaür, Atalanta, 2014.

Bowra, Cecil Maurice. La imaginación romántica. Madrid, Taurus, 1972.

Brewer, John. The Pleasures of the Imagination. English Culture in the Eighteenth Century. Chicago, The University of Chicago Press, 2000.

Cassirer, Ernst. Filosofía de la Ilustración. México D. F., Fondo Cultura Económica, 1975. Chevrier, Jean-François. L’hallucination artistique. París, Arachnéen, 2012.

Coleridge, Samuel Taylor. Biographia literaria. Londres, J. M. Dent \& Sons Ltd., 1977.

Corbin, Henry. La imaginación creadora en el sufismo de Ibn Arabi. Barcelona, Destino, 1993.

-- El hombre de luz en el sufismo iranio. Madrid, Siruela, 2000.

Goethe, Johann Wolfgang von. Escritos de arte. Madrid, Síntesis, 1999.

Gómez de Liaño, Ignacio. El idioma de la imaginación. Ensayos sobre la memoria, la imaginación y el tiempo. Madrid, Taurus, 1992.

Faivre, Antoine. "La théosophie chrétienne au XVII ${ }^{\mathrm{e}}$ siècle". 20 clés pour comprendre l'ésotérisme. En Antoine Faivre [et altri]. París, Albin Michel, 2013, pp. 77-80.

Ferrer-Ventosa, Roger. "Pensando en imágenes jeroglíficas: de la tradición hermética en el Renacimiento a las vanguardias hasta el arte contemporáneo”. Arte, individuo y sociedad, vol. 30, n. ${ }^{\circ 2}$, 2018, pp. 311-328. Doi: https://doi.org/10.5209/ ARIS.56941

Guillén, Esperanza. Retratos del genio. El culto a la personalidad artística en el siglo XIX. Madrid, Cátedra, 2007.

Harpur, Patrick. El fuego secreto de los filósofos. Vilaür, Atalanta, 2006.

- - "Introducción a los Libros proféticos de William Blake". Libros Proféticos I. William Blake. Vilaür, Atalanta, 2013, pp. 9-22.

Hobbes, Thomas. Leviatán. México, Fondo de Cultura Económica, 1984.

Horkheimer, Max y Theodor W. Adorno. Dialéctica de la Ilustración. Madrid, Trotta, 2001.

Keats, John. Odas y sonetos. Madrid, Hiparión, 2006.

Lachman, Gary. A Dark Muse. A History of the Occult. Nueva York, Thunder's Mouth Press, 2005 (e-book).

- - . The Quest for Hermes Trismegistus. Edimburgo, Floris Books, 2011 (e-book).

Lahelma, Marja. "The Symbolist aesthetic and the impact of occult and esoteric ideologies on modern art". Approaching Religion, vol. 8, n. ${ }^{\circ}$ 1, 2018, pp. 31-47.

Levi Ian Gentzke, Joshua. "Imagining the Image of God: Corporeal Envisioning in the Theosophy of Jacob Böhme". Lux in Tenebris. The Visual and the Symbolic in Western Esotericism. Ed. Peter Forshaw. Leiden/Boston, Brill, 2017, pp. 103-129.

Lincoln, Andrew. "Commentary on the text and the plates". Songs of Innocence and of Experience. Blake's Illuminated Books. Volume 2. William Blake. Londres, Tate Gallery, 1991.

Platón. Diálogos vi (Filebo, Timeo, Critias). Madrid, Gredos, 1992. 
Plotino. Enéadas II (III-IV). Madrid, Gredos, 1985.

Plotino y Porfirio. Enéadas I (Libros I-II) y Vida de Plotino. Madrid, Gredos, 1992.

Raine, Kathleen. Ocho ensayos sobre Blake. Vilaür, Atalanta, 2013.

Schmidgall, Gary. "Triangulating Blake, Whitman, and Ginsberg”. Walt Whitman Quarterly Review, vol. 32, n. ${ }^{\circ} 3$, 2015, pp. 131-143. Doi: https://doi.org/10.13008/07370679.2152

Spector, Sheila A. "Blake, William, * 28.11.1757 London, † 12.9.1827 London". Dictionary of Gnosis \& Esotericism. Ed. Wouter Hanegraaff. Leiden-Boston, Brill, 2006, pp. 173-177.

Starobinski, Jean. La relación crítica (Psicoanálisis y literatura). Madrid, Taurus, 1974. Thompson, Carl. The Suffering Traveller and the Romantic Imagination. Nueva York, Oxford University Press, 2007.

Valero, Alejandro. "Introducción”. Odas y sonetos. John Keats. Madrid, Hiparión, 2006, pp. 7-24.

Warnock, Mary. Imagination. Londres, Faber \& Faber, 1976.

Whale, John. Imagination Under Pressure, 1789-1832. Aesthetics, Politics and Utility. Cambridge, Cambridge University Press, 2004.

Wordsworth, Jonathan. “The Romantic Imagination”. A Companion to Romanticism. Ed. Duncan Wu. Oxford, Blackwell Publishing, 1999, pp. 525-533.

Wordsworth, William. "Preface to Lyrical Ballads (1800)". Prefaces and prologues to famous books, with introductions, notes and illustrations. Nueva York, P. F. Collier \& Son, 1910, pp. 283-305.

Yeats, William Butler. Essays on Symbolism / Ensayos sobre simbolismo. San Lorenzo del Escorial, Langre, 2005.

Enviado: 28 de diciembre de 2018 Aceptado: 8 de febrero de 2020 